\title{
Prevalence and trends of mental disorders requiring inpatient care in the city of Porto Alegre: a citywide study including all inpatient admissions due to mental disorders in the public system from 2013-2017
}

\author{
Prevalência e tendências temporais de transtornos mentais necessitando de tratamento \\ de internação na cidade de Porto Alegre: um estudo de toda a cidade incluindo todas as \\ internações por motivo de saúde mental no sistema público de 2013-2017
}

Giovanni A. Salum, ${ }^{1,2,3}$ (D) Loiva dos S. Leite, ${ }^{3}$ Sara Jane E. dos Santos, ${ }^{3}$ Gabriel Mazzini, ${ }^{3}$ Fernanda L. C. Baeza, ${ }^{1,2}$ Lucas Spanemberg, ${ }^{1,2,4}$ (D) Sara Evans-Lacko, ${ }^{5}$ (D) João Ricardo Sato, ${ }^{6}$ Diane M. do Nascimento, ${ }^{3}$ Thiago Frank, ${ }^{3}$ Juliana Pfeil, ${ }^{3}$ Natan Katz, ${ }^{3}$ Jorge Osório, ${ }^{3}$ Paulo Ricardo dos Santos, ${ }^{3}$ Eliana da Silva, ${ }^{3}$ Christiane Nunes, $^{2}$ Kelma Nunes Soares, ${ }^{3}$ Ângela Maria Grando Machado, ${ }^{3}$ Tatiana Breyer, ${ }^{3}$ Márcio Rodrigues, ${ }^{3}$ Adriani Galão, ${ }^{3}$ Gledis Lisiane Motta, ${ }^{3}$ Silvia Schuch, ${ }^{3}$ Eduardo Osório, ${ }^{3}$ Cláudia Rodrigues, ${ }^{3}$ Pablo de Lannoy Sturmer, ${ }^{3}$ Erno Harzheim $^{3,7}$

\begin{abstract}
Objectives: To investigate the 5 -year prevalence of patients admitted to public inpatient care units due to a mental disorder, stratifying them by age group and diagnosis, and to assess trends of admissions over this time period in Porto Alegre.

Methods: All admissions to the public mental health care system regulated by the city-owned electronic system Administração Geral dos Hospitais (AGHOS) were included in the analysis. The total population size was obtained by estimations of Fundação de Economia e Estatística (FEE). General information about 5-year prevalence of inpatient admissions, time-series trends e prevalence by age groups and diagnosis were presented.

Results: There were 32,608 admissions over the 5 -year period analyzed. The overall prevalence of patients was $1.62 \%$ among the total population, $0.01 \%$ among children, $1.12 \%$ among adolescents, $2.28 \%$ among adults and $0.93 \%$ among the elderly. The most common diagnosis was drug-related, followed by mood, alcohol-related and psychotic disorders. There was a linear trend showing an increase in the number of admissions from 2013 to the midst of 2014, which dropped in 2015.

Conclusions: Admissions due to mental disorders are relatively common, mainly among adults and related to drug use and mood disorders. Time trends varied slightly over the 5 years. Prevalence rates in real-world settings might be useful for policymakers interested in planning the public mental health system in large Brazilian cities. Keywords: Mental disorders, prevalence, inpatient care, admissions, public health.
\end{abstract}

\footnotetext{
${ }^{1}$ Departamento de Psiquiatria e Medicina Legal, Universidade Federal do Rio Grande do Sul (UFRGS), Porto Alegre, RS, Brazil. ${ }^{2}$ Seção de Afetos Negativos e Processos Sociais, Hospital de Clínicas de Porto Alegre (HCPA), Porto Alegre, RS, Brazil. ${ }^{3}$ Secretaria Municipal da Saúde, Prefeitura Municipal de Porto Alegre, Porto Alegre, RS, Brazil. ${ }^{4}$ Núcleo de Formação em Neurociências, Escola de Medicina, Pontifícia Universidade Católica do Rio Grande do Sul (PUCRS), Porto Alegre, RS, Brazil. ${ }^{5}$ London School of Economics and Political Science, London, United Kingdon. ${ }^{6}$ Universidade Federal do ABC, São Paulo, SP, Brazil. 7 Departamento de Medicina Social, UFRGS, Porto Alegre, RS, Brazil.

Submitted Dec 21 2018, accepted for publication Jul 04 2019. Epub Jan 102020.

Suggested citation: Salum GA, Leite LS, dos Santos SJE, Mazzini G, Baeza FLC, Spanemberg L, et al. Prevalence and trends of mental disorders requiring inpatient care in the city of Porto Alegre: a citywide study including all inpatient admissions due to mental disorders in the public system from 2013-2017. Trends
} Psychiatry Psychother. 2020;42(1):86-91. http://dx.doi.org/10.1590/2237-6089-2018-0115 


\section{Introduction}

Only a minority of individuals affected by mental disorders around the world have access to treatment. ${ }^{1}$ This important treatment gap is even more profound in low- and middle-income countries (LMICs)..$^{2-4}$ To address this gap, it is essential to incorporate a public health approach in health systems. In LMICs, one of the barriers to building effective mental health systems is the scarcity of credible data that reflect population needs, including of those individuals who would benefit most from specialized mental health care.

From a clinical perspective, the need for psychiatric admission reflects to a great extent the severity of a mental health disorder and also limited functionality. After the first psychiatric admission there is a significant increase in the risk of premature all-cause mortality and a strong increase in the number of deaths, especially by suicide. ${ }^{5}$ These findings reinforce the importance of focusing on patients requiring psychiatric inpatient care as a key population that needs attention from a public health perspective. Understanding the demands of the population with the greatest need for care can reveal important information toward preventive efforts.

Data on existing patterns of inpatient service utilization represent a fundamental piece of information to understand current resource utilization at its highest level and can guide public health management towards the best application of resources, planning of services and establishment of attainable goals in mental health, ${ }^{6}$ particularly in countries with integrated public health systems, like Brazil. The Brazilian Unified Health System (Sistema Único de Saúde [SUS]) is one of the largest public health programs in the world, and covers about $70 \%$ of the population. It complies with the principles of universality, integrality, equity and decentralization, from the primary level of health care to the secondary and tertiary levels. Despite that, no citywide perspectives are available to provide such prevalence rates in Brazilian cities.

The aim of this study was twofold: 1 ) to investigate the 5-year prevalence of patients admitted to public inpatient health care units in the municipality of Porto Alegre due to a mental disorder, stratified by age group and diagnosis; and 2) to investigate time trends of inpatient admissions over this time period.

\section{Methods}

Data about all mental health admissions to any inpatient unit that receives mental disorders (a total of 17 units) through SUS between 2013 to 2017 in the municipality of Porto Alegre were extracted from the city-owned electronic system Administração Geral dos Hospitais (AGHOS), a database covering all hospital admissions in the public health system of Porto Alegre, which represents $70 \%$ of residents. ${ }^{7}$ The city has about 466 contracted psychiatric beds in 11 institutions (general hospitals and specialized hospitals); the number of beds per institution varies from 10 to 150 . Admissions are regulated by two psychiatric emergency services with 14 beds each operating at $200 \%$ of their capacity.

To calculate 5-year prevalence estimates, the numerator was the number of patients with at least one admission between 2013 and 2017. Readmissions were excluded using the consolidated information of the system, which considers the patient's name, demographic information and registration records, because our main objective was to calculate the overarching prevalence for the overall time frame. The denominator was the total number of residents $(1,478,229$ people), extracted from estimates issued by Fundação de Economia e Estatística (FEE), ${ }^{8}$ available for the years 2013 to 2016. Estimates were adjusted to reflect only the number of residents who depend solely on the public system for healthcare, i.e., $70 \%$ of the residents $(1,034,760$ people) .

We also calculated the rates of the main diagnosis, based on the discharge code, defined according to criteria from the International Classification of Diseases, 10th revision (ICD-10). ${ }^{9}$ We created 14 broad categories that encompass 59 ICD-10 codes included in the database (data available as online-only supplementary material). For patients admitted more than once, and for those admitted with more than one diagnosis, one ICD-10 code was randomly selected. For calculating trends over time, we used a time series decomposition analysis that separates time trends from seasonal influences. For these analyses, all first-time admissions and readmissions were used, given the aim to investigate the general trends in admissions over time.

The institutional review boards from Hospital de Clínicas de Porto Alegre and Secretaria da Saúde de Porto Alegre approved the study.

\section{Results}

Overall there were 32,608 admissions to public mental health inpatient units in the city over the 5 years analyzed, totaling 16,794 patients admitted at least once (and 15,814 readmissions). The number of admissions per patient ranged from 1 to 44 over this time period (median $=1$ ). The overall 5 -year prevalence 
of patients admitted was $1.62 \%$ in the total population, $0.01 \%$ in children, $1.12 \%$ in adolescents, $2.28 \%$ in adults and $0.93 \%$ in the elderly.

The prevalence of mental disorders among individuals admitted to a hospital varied according to age (Table 1 and Figures S1 and S2, available as onlineonly supplementary material). In general, drug-related and mood disorders were the most prevalent disorders in adolescents and adults, mood and alcohol-related disorders in elderly, and mood and autism spectrum disorders in children.

According to time series decomposition analysis, the trends of all admissions over time revealed a slight seasonal variation, with the lowest number of admissions occurring in May and the highest in November (Figure 1). There was also a linear trend showing an increase in the number of admissions from 2013 to the midst of 2014, dropping in 2015, with a monthly mean of admissions of $543.2(S D=69.34)$ in the following years.

\section{Discussion}

According to our results, over the past 5 years, inpatient admissions due to mental disorders were relatively common in adolescents, adults and in the elderly, but rare in children. A prevalence of $1.62 \%$ was found for the total population, with higher rates in adults. The most common diagnoses in the total sample were drug-related disorders, followed by mood, alcohol-related and psychotic disorders, but there were important differences across the age groups. There was a linear trend showing an increase in the number of admissions from 2013 to the midst of 2014, which again dropped in 2015 and subsequent years.

To the best of the authors' knowledge, this is the first study to investigate the prevalence of people with mental disorders admitted to inpatient care units in a large Brazilian city, whereas previous efforts to estimate rates of inpatient utilization were limited to specific hospital settings, ${ }^{10,11}$ Brazilian states, ${ }^{12-14}$ and age groups. ${ }^{15,16}$ Notwithstanding, those previous studies did not investigate the prevalence of first-time hospitalizations in these populations, since they did not exclude rehospitalizations, but rather investigated temporal trends or frequencies of hospital records according to groups of disorders. Moreover, most of those studies used data from the Information Technology Department of the Brazilian Unified Health System (DATASUS), which is limited to estimating current hospitalization rates, as new records are created after 30 days of the previous hospitalization, and it is not possible to discriminate

Table 1 - Estimated prevalence of mental disorder requiring inpatient admission over 5 years, stratified by age group

\begin{tabular}{|c|c|c|c|c|c|c|c|c|c|c|c|c|c|c|c|}
\hline \multirow[b]{4}{*}{ Disorders* } & \multicolumn{15}{|c|}{ Average population size (2013-2016) } \\
\hline & \multirow{2}{*}{\multicolumn{3}{|c|}{$\begin{array}{c}\begin{array}{c}\text { Children } \\
(0-9 \text { years })\end{array} \\
125,849 \\
\end{array}$}} & \multirow{2}{*}{\multicolumn{3}{|c|}{$\begin{array}{c}\begin{array}{c}\text { Adolescents } \\
(10-19 \text { years })\end{array} \\
137,856\end{array}$}} & \multirow{2}{*}{\multicolumn{3}{|c|}{$\begin{array}{c}\begin{array}{c}\text { Adults } \\
(20-59 \text { years })\end{array} \\
598,654\end{array}$}} & \multirow{2}{*}{\multicolumn{3}{|c|}{$\begin{array}{c}\begin{array}{c}\text { Elderly } \\
(\geq 60 \text { years })\end{array} \\
172,399\end{array}$}} & \multicolumn{3}{|c|}{ Total } \\
\hline & & & & & & & & & & & & & & 1,034, & 760 \\
\hline & $\mathbf{n}$ & $\%$ & Prevalence & $\mathbf{n}$ & $\%$ & Prevalence & $\mathbf{n}$ & $\%$ & Prevalence & $\mathbf{n}$ & $\%$ & Prevalence & $\mathbf{n}$ & $\%$ & Prevalence \\
\hline $\begin{array}{l}\text { Autism } \\
\text { spectrum }\end{array}$ & 5 & 29.4 & $0.00397 \%$ & 17 & 1.100 & $0.01233 \%$ & 8 & 0.059 & $0.00134 \%$ & 0 & 0.000 & $0.00000 \%$ & 30 & 0.179 & $0.00290 \%$ \\
\hline $\begin{array}{l}\text { Intellectual } \\
\text { disability }\end{array}$ & 2 & 11.8 & $0.00159 \%$ & 48 & 3.105 & $0.03482 \%$ & 151 & 1.108 & $0.02522 \%$ & 6 & 0.376 & $0.00348 \%$ & 207 & 1.233 & $0.02000 \%$ \\
\hline $\begin{array}{l}\text { Organic } \\
\text { syndrome }\end{array}$ & 0 & 0.0 & $0.00000 \%$ & 1 & 0.065 & $0.00073 \%$ & 30 & 0.220 & $0.00501 \%$ & 43 & 2.693 & $0.02494 \%$ & 74 & 0.441 & $0.00715 \%$ \\
\hline Conduct & 2 & 11.8 & $0.00159 \%$ & 100 & 6.468 & $0.07254 \%$ & 9 & 0.066 & $0.00150 \%$ & 0 & 0.000 & $0.00000 \%$ & 111 & 0.661 & $0.01073 \%$ \\
\hline $\begin{array}{l}\text { Obsessive- } \\
\text { compulsive }\end{array}$ & 0 & 0.0 & $0.00000 \%$ & 0 & 0.000 & $0.00000 \%$ & 10 & 0.073 & $0.00167 \%$ & 1 & 0.063 & $0.00058 \%$ & 11 & 0.065 & $0.00106 \%$ \\
\hline Alcohol-related & 0 & 0.0 & $0.00000 \%$ & 5 & 0.323 & $0.00363 \%$ & 1,500 & 11.002 & $0.25056 \%$ & 442 & 27.677 & $0.25638 \%$ & 1,947 & 11.593 & $0.18816 \%$ \\
\hline Drug-related & 1 & 5.9 & $0.00079 \%$ & 612 & 39.586 & $0.44394 \%$ & 5,649 & 41.433 & $0.94362 \%$ & 54 & 3.381 & $0.03132 \%$ & 6,316 & 37.609 & $0.61038 \%$ \\
\hline Eating & 0 & 0.0 & $0.00000 \%$ & 5 & 0.323 & $0.00363 \%$ & 18 & 0.132 & $0.00301 \%$ & 1 & 0.063 & $0.00058 \%$ & 24 & 0.143 & $0.00232 \%$ \\
\hline Personality & 0 & 0.0 & $0.00000 \%$ & 23 & 1.488 & $0.01668 \%$ & 68 & 0.499 & $0.01136 \%$ & 2 & 0.125 & $0.00116 \%$ & 93 & 0.554 & $0.00899 \%$ \\
\hline Mood & 6 & 35.3 & $0.00477 \%$ & 532 & 34.411 & $0.38591 \%$ & 4,037 & 29.610 & $0.67435 \%$ & 706 & 44.208 & $0.40952 \%$ & 5,281 & 31.446 & $0.51036 \%$ \\
\hline Dissociative & 0 & 0.0 & $0.00000 \%$ & 0 & 0.000 & $0.00000 \%$ & 4 & 0.029 & $0.00067 \%$ & 1 & 0.063 & $0.00058 \%$ & 5 & 0.030 & $0.00048 \%$ \\
\hline Anxious/phobic & 0 & 0.0 & $0.00000 \%$ & 2 & 0.129 & $0.00145 \%$ & 11 & 0.081 & $0.00184 \%$ & 1 & 0.063 & $0.00058 \%$ & 14 & 0.083 & $0.00135 \%$ \\
\hline Psychotic & 0 & 0.0 & $0.00000 \%$ & 184 & 11.902 & $0.13347 \%$ & 2,117 & 15.527 & $0.00334 \%$ & 336 & 21.039 & $0.19490 \%$ & 2,637 & 15.702 & $0.25484 \%$ \\
\hline Others & 1 & 5.9 & $0.00079 \%$ & 14 & 0.906 & $0.01016 \%$ & 20 & 0.147 & $0.00334 \%$ & 4 & 0.250 & $0.00232 \%$ & 39 & 0.232 & $0.00377 \%$ \\
\hline Total & 17 & 100 & $0.01351 \%$ & 1,546 & 100 & $1.12146 \%$ & 13,634 & 100 & $2.27744 \%$ & 1,597 & 100 & $0.92634 \%$ & 16,794 & 100 & $1.62299 \%$ \\
\hline
\end{tabular}

* According to the International Classification of Diseases, 10th revision (ICD-10).

If the patient was admitted due to distinct ICD-10 codes in the 5 years analyzed, only one ICD-10 code was randomly selected.

88 - Trends Psychiatry Psychother. 2020;42(1) 
between new admissions and new records of the same hospitalization that continued (the unit of analysis is the record, not the individual). ${ }^{13,15}$ In order to compare the proportion of people affected by mental disorders in the community and estimate access to inpatient care, it is important to investigate evidence from community samples. Only one study using probabilistic sampling was conducted in the city of Porto Alegre in 1991 using a community sample. ${ }^{17}$ That study showed that mental disorders affected $42.5 \%$ of the sample, with $33.7 \%$ of those with a mental disorder utilizing treatment from a mental health professional. The most common diagnoses in that study were phobias $(14.1 \%)$, followed by depressive states $(10.2 \%)$, anxiety disorders (9.6\%) and alcohol abuse/dependence (9.2\%). Drug abuse/ dependence was not assessed in that study. If we assume those rates are still valid in the community, we can observe that phobias and anxiety disorders are less likely to require inpatient care, because the number of admissions due to these conditions were very low in our sample; conversely, depressive states, alcohol- related and psychotic disorders were the leading causes of inpatient admission.

Studies conducted in different Brazilian states have investigated time series and changes in records of psychiatric admissions using DATASUS. ${ }^{12-14}$ Two of them found a $>50 \%$ increase in the number of hospitalizations in the states of Minas Gerais (between 2001 and 2013) ${ }^{12}$ and São Paulo (between 2000 and 2015). ${ }^{14}$ In São Paulo, hospitalization rates per group of disorders decreased in almost all groups, with the exception of substance-related disorders, where there was a substantial increase $(107 \%$, 91\% for men and 203\% for women in the period). ${ }^{14}$ In Minas Gerais, there was a linear trend towards a decrease in the proportional number of hospitalization records due to schizophrenia in the period, with an increasing tendency for mood and substance-related disorders. ${ }^{12}$ In both studies, the decrease in the supply of beds was cited as a factor related to the decrease in the number of hospitalization records. Another study, in the state of Rio Grande do Sul (whose capital is Porto Alegre), ${ }^{13}$ investigated changes

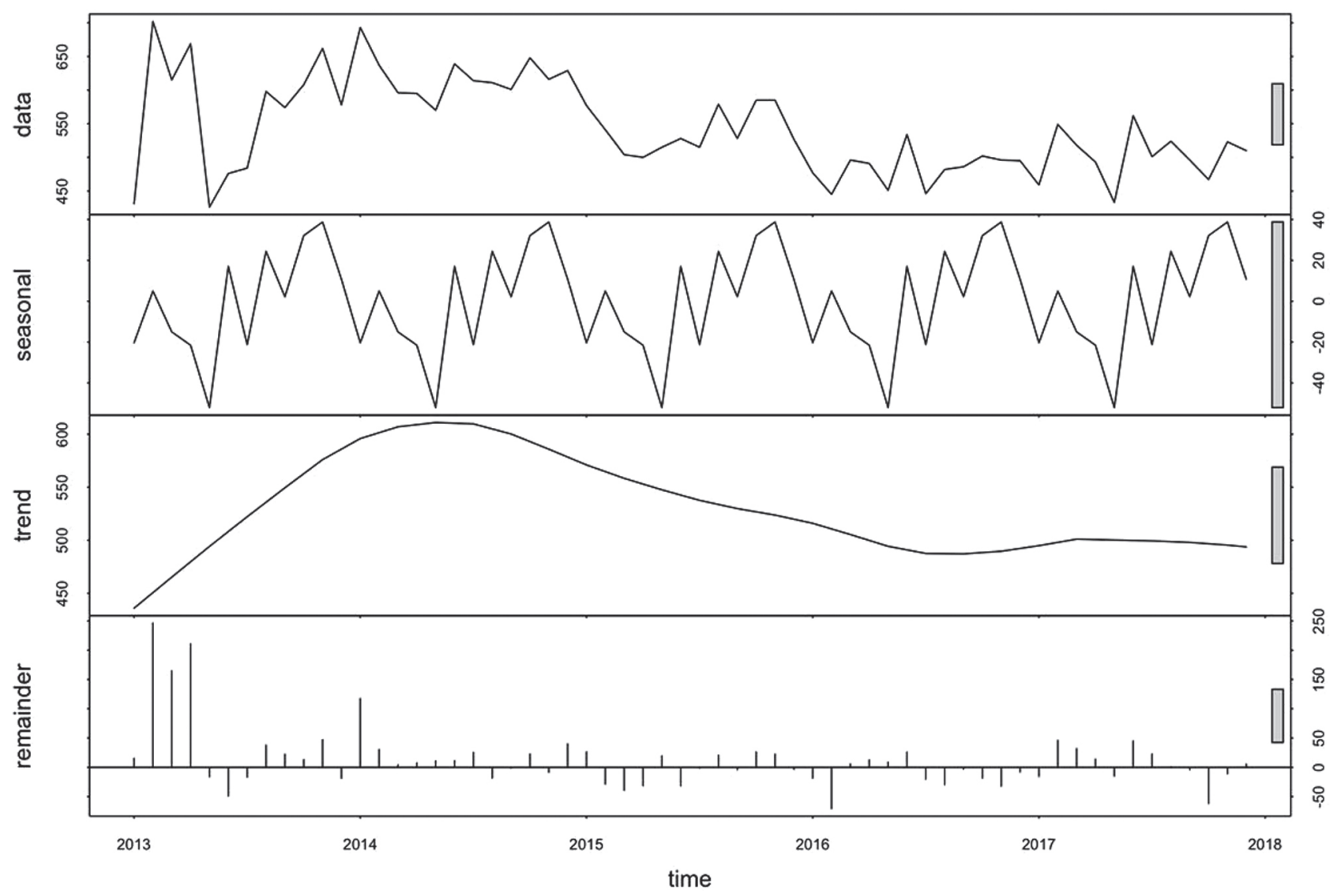

Figure 1 - Time series decomposition analysis for all admissions over the 5 years analyzed $(n=32,608)$ 
in hospitalization records in a smaller period (2000 to 2004). There was a small decrease in the number of records in the period (about 5\%), with a decrease in the linear trend in the proportion of hospitalizations due to schizophrenia and an increase in mood disorders (with stability for substance-related disorders). A probable explanation for the decrease in the number of hospitalizations and admission records in our study and in the country concerns the closure of psychiatric beds in Brazil. ${ }^{18}$ The psychiatric reform in the country has determined the replacement of beds in specialized hospitals with beds in general hospitals, and this process has not been occurring as recommended, resulting in a scenario of bed shortage and underfunding.

No nationally or regionally representative studies of prevalence are currently available; the most recent epidemiological study performed in the country was conducted in the city of São Paulo. ${ }^{19}$ That study showed a 12-month prevalence of mental disorders of $30 \%$ (20\% anxiety, $11 \%$ mood, $4.2 \%$ impulse control, $3.6 \%$ substance/drug), of which $10 \%$ were found to be severe. Also, that study showed that only $23.2 \%$ of severe disorders receive any mental health treatment, which represents $2.3 \%$ of the population of São Paulo (the authors, however, did not differentiate between outpatient and inpatient care). This is important when establishing public policies, and when estimating the demand of specialized mental health support in a city, despite some limitations commented on below.

This study has several strengths. First, to our knowledge, this is the first study to report the prevalence of psychiatric admissions in a citywide database in Brazil, with the possibility of estimating the actual prevalence of cases. Second, we were able to estimate the most common diagnoses in different age ranges, which is very helpful for service planning. However, there are also some limitations that should be considered. First, inpatient care is ultimately dependent on the number of psychiatric beds available, and this might directly impact the number of admitted patients. Second, data are limited to admissions that occurred in the public system, because the private sector is independent, but covers about $30 \%$ of the population of the city. Because the number of private beds in the city are estimated to account for half of the total number of beds in the city, our numbers are likely to be underestimated by the non-representation of this segment. Finally, ICD-10 diagnoses were registered based on clinical evaluation only and do not consider comorbid diagnoses. To minimize the effect of biased reporting of ICD-10 codes, we combined several diagnoses into groups of broad diagnostic categories, which are more likely to be consistent.
Evaluation of the prevalence of mental disorders in severely ill patients, such as psychiatric inpatients, is a first step toward a more accurate and systematic management process, where public policies and resource allocation rely on availability and information, directing efforts according to the actual demand of each city.

\section{Disclosure}

No conflicts of interest declared concerning the publication of this article.

\section{References}

1. Evans-Lacko S, Aguilar-Gaxiola S, Al-Hamzawi A, Alonso J, Benjet C, Bruffaerts R. Socio-economic variations in the mental health treatment gap for people with anxiety, mood, and substance use disorders: results from the WHO World Mental Health (WMH) surveys. Psychol Med. 2018;48:1560-71.

2. Shidhaye R, Lund C, Chisholm D. Closing the treatment gap for mental, neurological and substance use disorders by strengthening existing health care platforms: strategies for delivery and integration of evidence-based interventions. Int J Ment Health Syst. 2015;9:40.

3. Patel V, Thornicroft G. Packages of care for mental, neurological, and substance use disorders in low- and middle-income countries: PLoS Medicine Series. PLoS Med. 2009;6:e1000160.

4. Demyttenaere K, Bruffaerts R, Posada-Villa J, Gasquet I, Kovess $V$, Lepine JP. Prevalence, severity, and unmet need for treatment of mental disorders in the World Health Organization World Mental Health Surveys. JAMA. 2004;291:2581-90.

5. Walter F, Carr MJ, Mok PLH, Astrup A, Antonsen S, Pedersen CB, et al. Premature mortality among patients recently discharged from their first inpatient psychiatric treatment. JAMA Psychiatry. 2017;74:485-92.

6. Kilbourne AM, Beck K, Spaeth-Rublee B, Ramanuj P, O'Brien RW, Tomayasu $C$. Measuring and improving the quality of mental health care: a global perspective. World Psychiatry. 2018;17:308.

7. Silva ZP da, Ribeiro MCS de A, Barata RB, Almeida MF de. Perfil sociodemográfico e padrão de utilização dos serviços de saúde do Sistema Único de Saúde (SUS), 2003-2008. Cienc Saude Coletiva. 2011;16:3807-16.

8. Governo do Estado do Rio Grande do Sul, Fundação de Economia e Estatística. Estimativas populacionais [Internet]. [cited 2018 Aug 9]. https://www.fee.rs.gov.br/indicadores/populacao/ estimativas-populacionais/

9. World Health Organization. International Classification of Diseases, 11th Revision (ICD-11) [Internet]. [cited 2018 Aug 9]. http://www.who.int/classifications/icd/en/

10. Moreschi HK, Pavan G, Godoy JA, Mondrzak R, Almeida MR, Pacheco MA. Factors related to positive and negative outcomes in psychiatric inpatients in a General Hospital Psychiatric Unit: a proposal for an outcomes index. Arch Clin Psychiatry. 2015;42:612.

11. Baeza FL, Rocha D, S N, Fleck MP. Predictors of length of stay in an acute psychiatric inpatient facility in a general hospital: a prospective study. Rev Bras Psiquiatr. 2018;40:89-96.

12. Lara APM, Volpe FM. The evolution of the profile of psychiatric admissions via the Unified Health System in Minas Gerais, Brazil, 2001-2013. Cienc Saude Coletiva. 2019;24:659-68.

13. Candiago RH, Belmonte-de-Abreu P. Use of Datasus to evaluate psychiatric inpatient care patterns in Southern Brazil. Rev Saúde Pública. 2007;41:1-8.

14. Mendes JDV. Evolução das causas de internação de saúde mental no SUS do Estado de São Paulo, 2000 a 2015. São Paulo: Grupo Técnico de Avaliação e Informações de Saúde (Gais) - Secretaria de Estado da Saúde de São Paulo; 2016:1-10. [cited 2019 May 16]. http://portal.saude.sp.gov.br/resources/ses/perfil/ profissional-da-saude/destaques//gais_51_abril_2016.pdf 
15. Ritter PL, Dal-Pai D, Belmonte-de-Abreu P, Camozzato A. Trends in elderly psychiatric admissions to the Brazilian public health care system. Rev Bras Psiquiatr. 2016;38:314-7.

16. Santos $V$ dos, Fernández $A$. Child and adolescent mental health services in Brazil: structure, use and challenges. Rev Bras Saúde Matern Infant. 2014;14:319-29.

17. Almeida-Filho N, Mari J de J, Coutinho E, França JF, Fernandes J, Andreoli SB. Brazilian multicentric study of psychiatric morbidity. Methodological features and prevalence estimates. Br J Psychiatry. 1997;171:524-9.

18. Loch AA, Gattaz WF, Rössler W. Mental healthcare in South America with a focus on Brazil: past, present, and future. Curr Opin Psychiatry. 2016;29:264-69.
19. Andrade LH, Wang Y-P, Andreoni S, Silveira CM, Alexandrino-Silva C, Siu ER, et al. Mental disorders in megacities: findings from the São Paulo Megacity Mental Health Survey, Brazil. PloS One. 2012; 7:e31879.

\section{Correspondence:}

Lucas Spanemberg, MD, PhD

Hospital São Lucas da PUCRS, Unidade de Internação Psiquiátrica Av. Ipiranga, 6690, Jardim Botânico

90610-000 - Porto Alegre, RS - Brazil

Tel.: +55 (51) 997256293

E-mail: lucas.spanemberg@pucrs.br 